\title{
AC 2011-1007: ELECTRIC CIRCUITS ONLINE: TOWARDS A COMPLETELY ONLINE ELECTRICAL ENGINEERING CURRICULUM
}

\section{Yacob Astatke, Morgan State University}

Dr. Yacob Astatke completed both his Doctor of Engineering and B.S.E.E. degrees from Morgan State University (MSU) and his M.S.E.E. from Johns Hopkins University. He has been a full time faculty member in the Electrical and Computer Engineering (ECE) department at MSU since August 1994 and currently serves as the Associate Chair for Undergraduate Studies. He teaches courses in both analog and digital electronic circuit and communication systems design and instrumentation. Dr. Astatke has more than 15 years experience in the development and delivery of synchronous and asynchronous web-based course supplements for electrical engineering courses.

\section{Craig J. Scott, Morgan State University}

Dr. Craig Scott, Chair of the Electrical and Computer Engineering Department at Morgan State University, has extensive experience in the development of advanced engineering visualization tools and courseware. Additionally, he has been conducting empirical studies on effective learning technologies, as well as remedial math preparation for engineering students. He teaches courses in electromagnetics, solid state theory, characterization of semiconductor materials, computer vision and computational electrical engineering.

\section{Jumoke 'Kemi Ladeji-Osias, Morgan State University}

DR. JUMOKE LADEJI-OSIAS is an Associate Professor and Associate Chair for Graduate Studies in the Department of Electrical and Computer Engineering at Morgan State University. Kemi has experience in developing algorithms for synthetic vision systems. She teaches undergraduate and graduate courses in digital design. She has a B.S. degree in Electrical Engineering and a Ph.D. degree in Biomedical Engineering. 


\title{
Electric Circuits Online - Towards a Completely Online Electrical Engineering Curriculum
}

\begin{abstract}
This paper presents our experiences and results in developing and delivering two core Electrical and Computer Engineering (ECE) courses with laboratory components completely online using an internet based distance learning delivery system and the Mobile Studio technology and pedagogy. The challenge in offering ECE courses online is the fact they have a very intensive hands-on component, such as design and laboratory experiments, that require students to use expensive laboratory equipment to complete and demonstrate their projects. This implied that until now, institutions offering ECE laboratory courses had to have students attend the laboratory courses on their campuses. Our ECE department is in the process of redesigning and delivering all 200-level and 300-level electrical/electronic engineering core and laboratory courses utilizing unique and innovative distance learning technologies.
\end{abstract}

We successfully developed and delivered two pilot courses, "Electric Circuits", and "Introduction to Electrical Laboratory" completely online during the summer of 2010. Both courses, and a third course called "Introduction to Digital Design" are currently being offered completely online to students enrolled in our regular ECE program. This paper will present a detailed explanation on how we used the Mobile Studio technology to redesign and offer ECE laboratory experiments that can be conducted by students without using regular laboratory space and equipment. We also present detailed description on how we used the Adobe Connect ${ }^{\mathrm{TM}}$ software to allow the students to demonstrate their design and laboratory experiment circuits to the course instructor from a remote location. The results have shown that the students were able to conduct most of the design and laboratory experiments required in the regular courses without the need to be on campus. All the students enrolled in the pilot summer courses successfully completed the two ECE courses and are currently enrolled in the follow-up courses.

\section{Introduction}

Trends in higher education for the past 10 years have shown that enrollments in online courses or online degree programs have been growing substantially faster than overall higher education enrollment. A survey of online learning conducted in 2009 by the Sloan Consortium indicated that enrollment in one or more online courses reached 4.6 million students in $2008^{1}$. The 17 percent growth rate for online enrollments is significantly higher than the 1.2 percent growth rate of the overall higher education student population during the same time period ${ }^{2}$. The report of the survey entitled, "Learning on Demand: Online Education in the United States, $2009^{\prime \prime}$ seeks to address and provide answers to some of the fundamental questions related to the nature and extent of online education. Some of the questions addressed in the report are, whether retention of students is harder in online courses, if the learning outcomes in online courses are comparable to face-to-face courses, or the impact of the current economic conditions on online education. The authors of the survey conclude their report by stating that "online enrollments in U.S. higher education show no signs of slowing." 
One discipline that has lagged behind all others in the development and delivery of online education is engineering. While close to 320 engineering schools in the USA have received accreditation from the Accreditation Board for Engineering and Technology (ABET) for their undergraduate programs, only a handful of those offer engineering programs that are completely online at the graduate and/or undergraduate level. The trend has started to change lately, and every year more and more engineering programs are adding an online component to their regular curriculum. The main obstacle is the fact that most engineering curriculums require a very intensive hands-on laboratory component that is very hard to implement and deliver completely online because of the cost involved in setting up laboratory equipment for each online student.

The majorities of online engineering programs currently available are at the Master of Science level, and are geared towards professional engineers who have received their undergraduate degrees from a regular campus based program. A summary of the list of engineering programs that offer a Master of Science (MS) degree completely online is presented by the Sloan Consortium ${ }^{2}$. It should be noted that only one program, the Master of Science in Bioinformatics from Johns Hopkins University (JHU) is actually accredited by ABET. An even smaller number of institutions offer a completely online Bachelor of Science (BS) engineering degree program. They are listed below:

- University of North Dakota offers a Bachelor Science (BS) degree in the following engineering majors: Chemical, Civil, Electrical, and Mechanical.

- The State University of New York (SUNY) offers a completely online Electrical Engineering BS program at the following three campuses: Binghamton, Buffalo, and Stony Brooke.

The majority of the universities that offer an online engineering curriculum indicate to their students that their online program is separate and different from their regular on campus program. Some universities on the other hand make no differentiation between their online and their on campus degree programs. For example, the MS degrees in Chemical engineering offered at Kansas State, and North Carolina State and the BS degree in Chemical engineering offered the University of North Dakota are equivalent to the regular on campus degree programs. One way universities are assuring that their online engineering degree programs are as valuable as their on campus programs is by using various types of technologies to increase and enhance the learning experience of their online students.

Most schools provide online courses using live video and streaming technologies. For example, the University of Florida utilizes a distance learning delivery platform called the "UF Edge" to digitally record on-campus lectures and deliver them to online students anytime, anywhere. Similar approaches are utilized at other institutions ${ }^{3,4}$. This approach allows online students to have a very flexible academic schedule, while providing them with a learning experience that closely mirrors that of on-campus students. Johns Hopkins University's ABET accredited MS program in Bioinformatics uses a online delivery platform that allows live courses to be streamed to the students. JHU supplements the synchronous steaming technology with a web conferencing technology that allows students to participate in the class room in real time. Although the web-conferencing and synchronous streaming technology provide a high degree of interactivity to the online students, they put constraints on their scheduling flexibility. 
Another approach is to use technology that allows online students to attend live lectures delivered on campus to the regular students. Some schools also take into account the fact that online students might not have a stable and reliable internet connectivity by providing them with CD-ROMs and video tapes of the all the course contents.

The electrical engineering courses offered to online students at our institution will utilize various technologies and tools that are currently available and used by many other engineering schools with online programs. However, our approach is slightly different from the other two universities that offer a BS degree in Electrical engineering because we are able to utilize a new technology, the "Mobile Studio IOBoard ${ }^{\mathrm{TM}}$ " developed at Rensselaer Polytechnic Institute (RPI) to implement the laboratory and design components of our undergraduate courses. We also supplement our online courses with lecture captures of our regular on campus courses using the Panopto Focus $^{\mathrm{TM}}$ software. Finally, we use the Adobe Connect ${ }^{\mathrm{TM}}$ software to allow online students to demonstrate their projects and laboratory assignments to their instructors from another location. The results of our implementation in two courses are discussed in the rest of the paper.

\section{Course Development}

The development of the two online ECE courses discussed in this paper started about 10 years ago with the addition of web-based course supplements for the regular courses. The webbased course supplements consisted of additional course materials such as PowerPoint slides, animations, short video, and other website links that were there to help the regular students understand the course material better. Regardless of the amount of supplementary course materials available to the students, the one thing that was always required by all students is fact that they had to come to the ECE laboratory rooms and use the laboratory equipment to design, build, test and demonstrate their projects and laboratory experiments to the course instructor. This changed three years ago, when our university joined the Mobile Studio project that was funded by a five year NSF grant at RPI. The addition of the Mobile Studio IOBoard ${ }^{\mathrm{TM}}$ allowed us to redesign our regular and laboratory ECE courses in such a way that the students can now conduct the majority of their design and laboratory experiments outside of the ECE laboratories.

In the first phase of our implementation, regular students were allowed to use the Mobile Studio boards to complete their laboratory and design projects in their dorms or the library. However, they were still required to see the course instructor in his/her office or in the ECE laboratory to conduct a live demonstration of their final projects. The faculty at our institution worked with peers at other institutions involved in the Mobile Studio project to redesign various laboratory and design experiments so that they can be completed by the students using the Mobile Studio IOBoard ${ }^{\mathrm{TM}}$. The key issue that we had to address was the fact that the Mobile Studio IOBoard ${ }^{\mathrm{TM}}$ is limited to very low voltages (plus or minus 4 Volts) because it draws its power from the USB port of the laptop it is connected to. This implied that laboratory experiments that required a "Power Supply" or "Function Generator" with more than 5 volts had to be redesigned in such a way that the overall concept of the experiments could still be understood by the students. The instructors involved in the Mobile Studio project at the various institutions worked together very closely so that they all followed a very sound pedagogy to

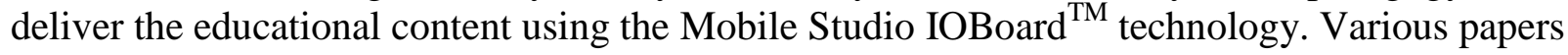


on the use of the Mobile Studio IOBoard ${ }^{\mathrm{TM}}$ technology and pedagogy have been published by the other members of the Mobile Studio project at several conferences ${ }^{5}$.

In the second stage of the implementation of our online courses, we started evaluating various hardware and software technologies that would make the course experience of online students as close as possible to the regular students. We had to carefully evaluate the advantages and disadvantages of synchronous and asynchronous modes of content delivery for our online students. Since our goal was to offer the online ECE courses to students from within the United States or abroad, we decided to use a tool that can offer both synchronous and asynchronous course contents to the online student. We decided to use the "Panopto Focus "TM " software which was available on campus. We used the Panopto Focus ${ }^{\mathrm{TM}}$ software to capture and record a synchronized version of the text (using PowerPoint), audio, and video from the daily lectures of the face-to-face ECE courses. This allowed the online students to follow the lectures and class discussions that occur in the regular courses at their own pace and time. The online lectures can be watched over the internet using streaming technology, or can be downloaded as podcasts. The only option that is not available to the online students while they are watching the streaming or podcast versions of the regular course lectures is the ability to ask questions of the course instructors in real time. This however does not prevent the online students from asking their questions at some other time using email, chat rooms, or over the telephone.

Although the first and second stages of the implementation of our online courses added more flexibility to our regular students, they were still required to come to the campus and use the ECE laboratories in order to demonstrate their design projects or laboratory experiments to their course instructors. We decided to use Adobe Connect ${ }^{\mathrm{TM}}$ video conferencing software in order to allow the students to complete their project and laboratory experiment demonstrations without physically being present on our campus. The Adobe Connect ${ }^{\mathrm{TM}}$ software allowed the course instructor to schedule an online project or laboratory experiment demonstration time with the students. This required both the students and the instructor to have access to laptops with audio/video cameras so that they can conduct the video conferencing more efficiently. Although we encountered some technical difficulties while trying to set-up the video cameras with the laptops and the Adobe Connect ${ }^{\mathrm{TM}}$ software, we were successful in proving that the students could actually conduct a project demonstration completely online from various off-campus locations. The online ECE project demonstrations were successfully conducted while the instructor was in Troy, New York, and the students were in New York City, NY and in Baltimore, Maryland. The following sections present the screen captures and other results that demonstrate the implementation of our first two ECE online courses.

\section{Course Delivery and Testing}

Although five of the six students enrolled in our two pilot ECE online courses had access to all the facilities on our campuses, the courses were conducted as if the students were completely online. Therefore, they were not required to come to our campus on a daily basis to download and view the lecture notes, to complete their project and lab assignments, or even demonstrate their project results. We took this approach to make sure that the online courses that we developed can indeed be offered completely online to any student as long as they had access to the Internet. The student who was off campus completed his course while working on his 
summer internship in New York City. He had to travel to our campus on two occasions to take his written exams and get parts for his projects and laboratory experiments.

\section{Phase I-Implementation of the Mobile Studio Technology and Pedagogy}

In this phase, our instructors worked very closely with other instructors involved in the Mobile Studio project to redesign the various laboratory and design projects required in the Electric Circuits and Introduction to Electrical Laboratory courses. Tables 1 to 4 show the contents of a sample laboratory experiment that was designed using the Mobile Studio IOBoard $^{\mathrm{TM}}$. Note that the concepts covered in this lab experiment are similar to those conducted using the regular lab equipment although different test instruments are used. All students have to initially complete a laboratory experiment that teaches them how to use the software and hardware of the Mobile Studio IOBoard ${ }^{\mathrm{TM}}$, and how it can be connected to circuits they design on their bread-boards. The survey and feedback questions shown in Table\#4 are given to the students at the end of each lab to get their feedback, comments and concerns regarding any part of the laboratory or design experiment.

\section{Table 1: Instructions on how to use the Mobile Studio IOBoard ${ }^{\mathrm{TM}}$.}

EEGR 202 Dr. Yacob Astatke

Mobile Studio (MS) Lab 4 - Thevenin Equivalent Circuit and Max Power Transfer

\section{Mobile Studio and Instrumentation Board}

MS is a technology-based new learning tool comprising a tablet PC (or any PC) and an instrumentation board, which replaces most of the lab equipment. Therefore, MS allows a small foot print, mobile laboratory experiments any place any time. The measurement by MS is possible by a Windows-based software, Mobile Studio Desktop, which is already installed in the tablet PCs. The icon for the Mobile Studio Desktop is illustrated below.
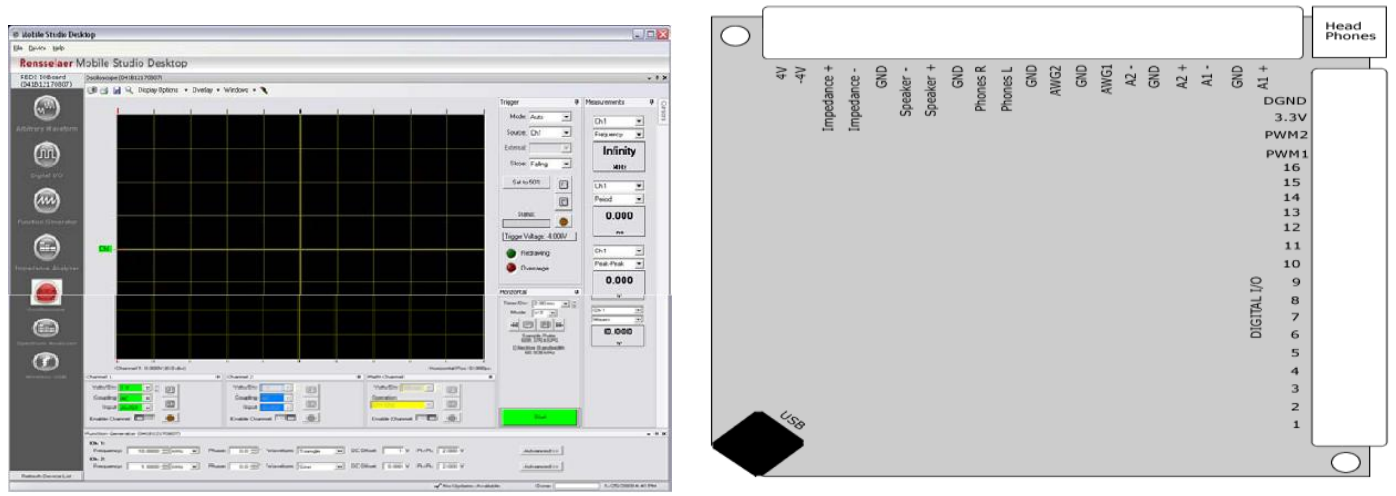

Figure \#1: Mobile Studio Desktop ${ }^{\mathrm{TM}}$ Software and Hardware Pin Layout

- As you see in the above picture, the instrumentation board is USB connected to the tablet PC. The instrumentation board can function as :

(a) scope, (b) Digital Multi Meter (DMM), (c) Power supply, and (d) Function generator.

- There are, however, important limitations in using the Red board

(1) No direct measurement of current -- You get current indirectly (by measuring voltage across a resistor, etc), or by using hand held multimeter.

(2) No direct measurement of resistance -- You get it indirectly (You may still need a DMM for resistance measurement), or by using hand held multimeter.

(3) There is no variable voltage unless you use a variable resistor. There are fixed voltages generated from the power supply sources. 


\section{Table \#4: Survey and Feedback questions given to the students}

\section{Logistics (* This section is not graded, but your honest answers would be appreciated. $\rightarrow$ You are required to enter your honest answer !!!)}

(a) What was most frustrating in the class and the use of the MStudio Board?

(b) What was most interesting in the class and the use of the MStudio Board?

(c) How much more do you understand the function and use of Thevenin's theorem after completing this design project ? Please write any additional comments. Choose one :
1. Not Confident
2. Fairly Confident
3. Confident
4. Extremely Confident

(d) How much are you comfortable with measuring voltage using the instrumentation board and tablet PC? Choose one :
1. Not Confident
2. Fairly Confident
3. Confident
4. Extremely Confident

(e) Was mobile studio pedagogy a helper (with your understanding and practice of circuit theory) or a distracter/nuisance? Choose one :
1. Did not help at all(distracter/nuisance)
2. Helped a little
3. Helped
4. Helped a lot

(f) Did you get your needed help from the discussion with your team member?

(g) Did you get your needed help from the instructor/TA? Satisfied?

\section{Phase II-Implementation of the Panopto Focus ${ }^{\text {TM }}$ Lecture Capture technology}

The "Panopto Focus ${ }^{\mathrm{TM}}$ " software was used to capture and record the daily course lectures of the regular ECE courses. It was initially tested on the students enrolled in the regular ECE courses as a supplementary material that could help them learn and understand the course material better. The students had access to daily course lectures through their Blackboard course management software. Most students downloaded podcast versions of the daily course lectures and watched them as often as they wanted until they understood the topics covered in each lecture. This approach increased the interactions and discussions between the students involved in the course. The online lectures also allowed the students to prepare and ask additional and more advanced questions to the instructor because it allowed them to have a better understanding of the course material since they were no more limited to the information that was only available in their own class notes. The statistics of the usage of the course lectures from the Electric Circuits course that were recorded from the Spring 2010 semester suggest that the students enrolled in the two pilot online summer courses found the Panopto Focus ${ }^{\mathrm{TM}}$ lecture recordings very valuable to their success in the courses. Table\#5 shows the view by month, and Table\#6 shows the detailed view statistics for each lesson recorded that was downloaded and viewed by the students. Note that some students are ahead of other students by checking the unique number of users for each lesson. For example, the lecture recordings for Module 5-part2, and Module 5-part3 have only 2 unique users indicating that 2 students are ahead of the other students. 


\section{Table \#5: Monthly statistics on the use of the lecture recordings}

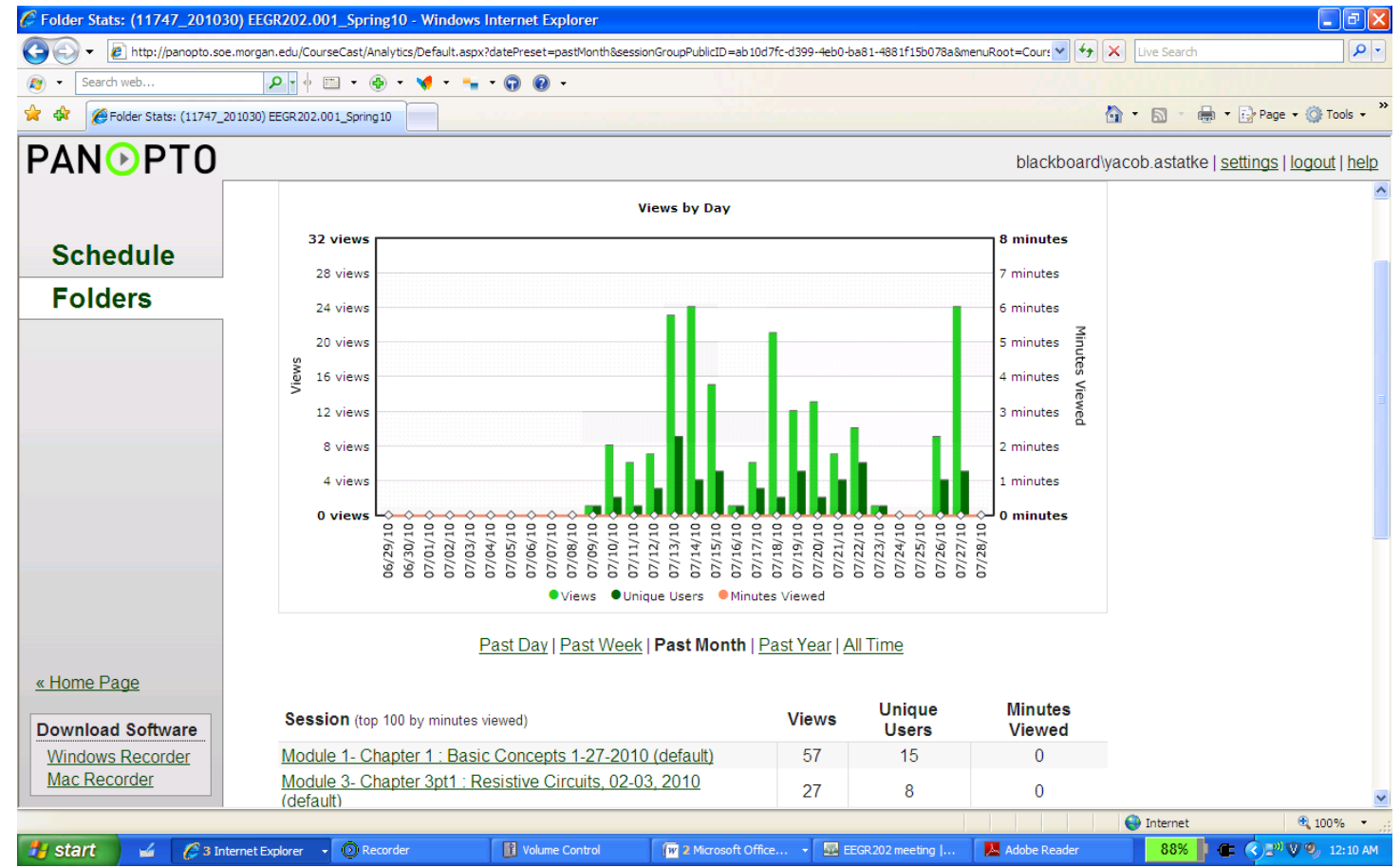

\section{Table \#6: Detailed statistics on the use of the lecture recordings}

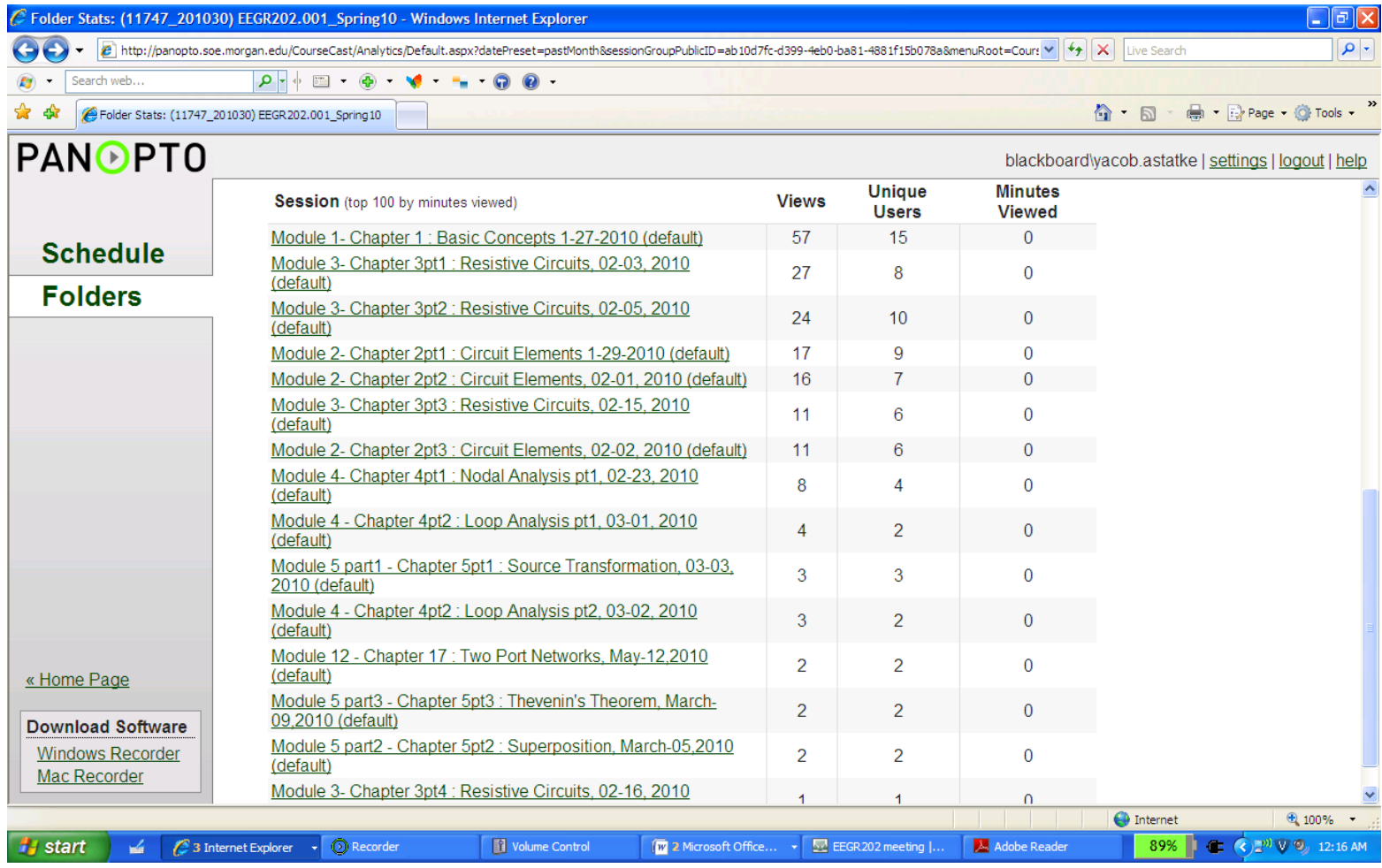




\section{Phase III-Implementation of the Adobe Connect Software}

Once phases I and II were implemented and tested on the regular students enrolled in the two ECE courses, the last stage of our project was figuring out a way of allowing students to demonstrate their project and laboratory experiments to their instructors without being present on our campus. Adobe Connect ${ }^{\mathrm{TM}}$ has been used by other institutions and corporations to conduct face-to-face video conferencing in real time. We decided to use it in our online ECE courses to test whether it can solve the final puzzle in our goal to provide undergraduate ECE courses completely online. The project demonstrations by the four students were conducted while the course instructor was in Troy, New York. Two students were in their dormitories in Baltimore, Maryland, a third student was off-campus in Baltimore, Maryland, and the fourth student was in New York City, NY. Three out of four students successfully demonstrated the results of their projects. The fourth student had issues with his video camera that prevented him from completing his project demonstration that day. He was able to fix his problem and complete his online project demonstration later that week. The screen captures shown in Figures \#1 and \#2 show how the instructor and the students were able to conduct the complete laboratory demonstration online. Note that in Figure\#2, other students can follow the demonstrations of their classmates while they wait for their turns.

\section{Figure \#1: Course Instructor giving instructions to the student}
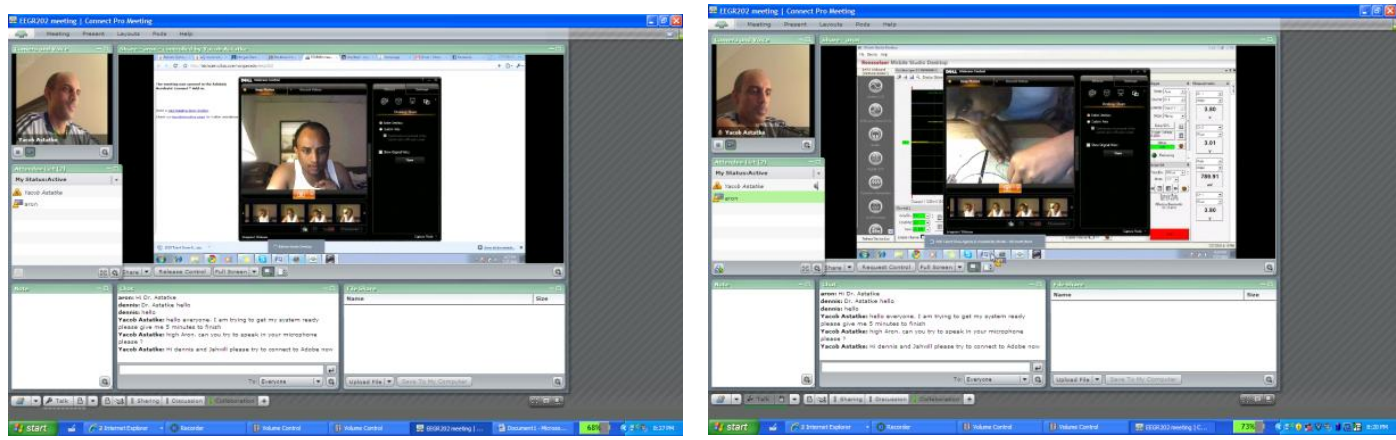

Figure \#2: Student making changes to his circuit and showing the results to the instructor
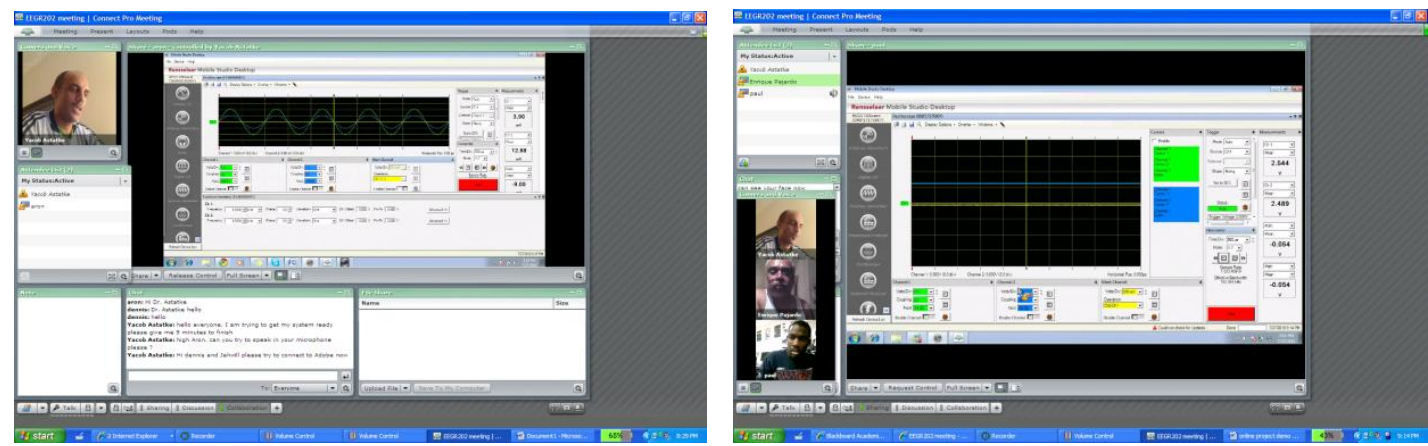


\section{Course Results}

The results of our two pilot courses are very encouraging although they suggest that more work needs to be done to make our online courses as effective and reliable as our regular courses. One of the key issues that we faced during the summer session is the shorttime available to complete the two courses. The students enrolled in the pilot online ECE courses only had seven weeks to cover the materials that we usually cover in 14 weeks. The problem became more significant when students had to complete their laboratory and design experiments on their own. That is because the learning curve required to be familiar with the functionalities of the Mobile Studio IOBoards ${ }^{\mathrm{TM}}$ was steep. Since we did not have enough written documentation such as user manuals and troubleshooting tips on the Mobile Studio boards, the students had a difficult time completing their first laboratory assignment. Afterwards, their confidence level increased and they were able to successfully complete the remaining laboratory and design project experiments.

The students enrolled in the pilot online courses were given the same projects, homework assignments, and tests as the students enrolled in the regular courses. Although the students enrolled in the online course covered the same amount of material as the regular students, they were only given two hand written exams on campus instead of three or four exams that are given to the regular students. They were given the exams on campus because they were all local students. This will not be a requirement for future online students because we plan to form partnerships with test centers or learning centers to allow them to take their exams from other locations. Due to time constraints and technical difficulties, the students enrolled in the pilot summer online courses completed fewer design projects compared to the regular students. Several of the topics covered in the regular course were combined into two projects instead of the usual three or four projects that are given in the regular course. All the students enrolled in both the "Electric Circuits," and "Introduction to Electrical Laboratory" pilot courses completed both courses successfully. However, their grade distributions were much lower compared to the 25 students enrolled in the regular course during the previous Spring 2010 semester as shown in Figure\#3 below.

\section{Figure \#3: Student performance comparison in Electric Circuits Course}

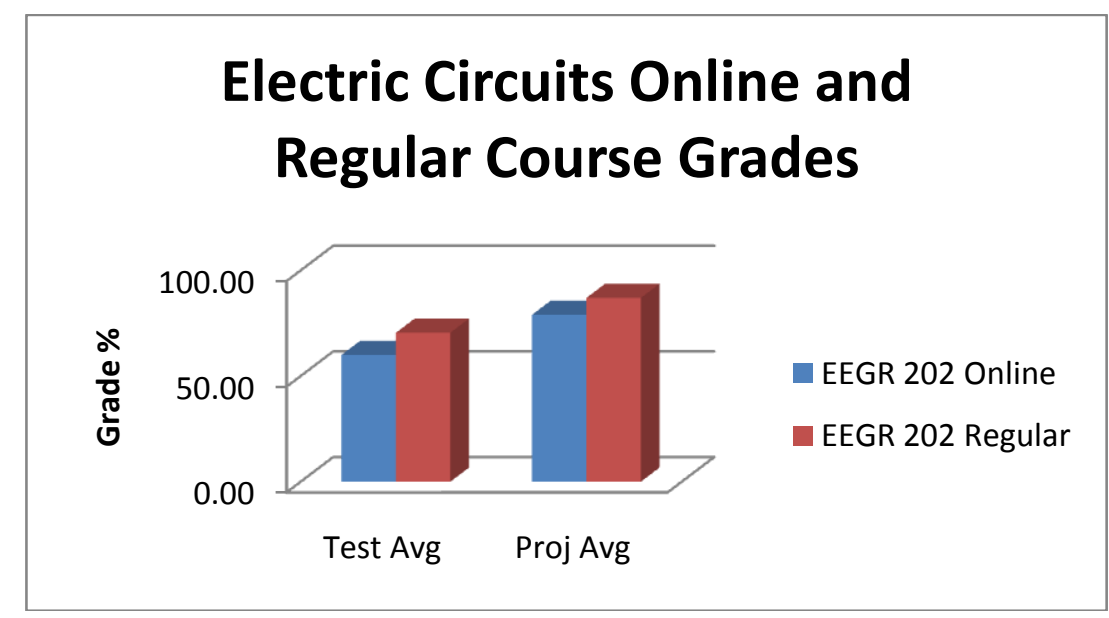


This can be due to several factors. They initially had some technical difficulties downloading and viewing the Panopto Focus ${ }^{\mathrm{TM}}$ lecture recordings on their computers. The fact that the pilot courses employed several new technologies and pedagogies that the students were not familiar with, increased the learning curve of the students. The main reason is the lack of adequate time to study and understand the topics covered in each lesson in the summer pilot courses. Therefore, we only plan to offer the two ECE courses during the regular semester in the future and not during the summer sessions.

\section{Summary and Conclusion}

We have learned from the experiences of the two pilot courses and have taken additional steps to improve current and future online ECE courses offered at our institutions. We have already developed several additional training and teaching materials that clearly explain how to use the Mobile Studio IOBoards ${ }^{\mathrm{TM}}$ to future online students. All the laboratory experiments that were given to the students enrolled in the pilot summer courses have been updated and improved during the Fall 2010 semester. We had the chance to test and evaluate new and improved laboratory experiments using the regular students enrolled in the two ECE courses. The instructor has recorded additional lecture notes for both pilot courses using the Panopto Focus ${ }^{\mathrm{TM}}$ software in the Fall 2010 semester. This implies that students taking the two online ECE courses in the future will have access to additional lecture notes, example and homework problems, test and quiz solutions that were given in both the Spring 2010 and the Fall 2010 semesters. The other issue that we have to address is the approach used for administering exams to future online students. We plan to use test centers or learning centers that are available in most cities and towns to allow our online students to take their exams without the need to travel to our campus. This approach is currently used by most programs that offer online courses to their students. We also plan to evaluate other portable ECE laboratory kits such as the National Instrument (NI) myDAQ ${ }^{\mathrm{TM}}$ boards to evaluate their performances and compare them to the Mobile Studio IOBoards $^{\mathrm{TM}}$.

Although both the Mobile Studio technology, and the Adobe Connect ${ }^{\mathrm{TM}}$ software have previously been used separately by other institutions for similar applications, to the best of our knowledge no other higher education institution in the United States has combined both technologies to offer ECE undergraduate courses completely online. This new approach represents a major paradigm shift in the way higher education institutions should think when delivering Electrical Engineering education. We hope that it will open the door to many students who are candidates for joining the science, technology, engineering and mathematics workforce such as, current and new personnel relocating to new military bases, mid-career employees, and ex-military personnel because they typically require the opportunity to continue to earn a living while pursing their education and are most often unable to relocate to college campuses for the two to three years required to complete the requisite courses for a Bachelor's degree. Online education is here to stay, therefore we hope that engineering schools nationwide can follow the path set by the other disciplines ${ }^{6}$. 


\section{References}

${ }^{1}$ E. Allen, J. Seaman, “Learning on Demand: Online Education in the United States ,2009” The Sloan Consortium, published January2010.

2 The Sloan Consortium, Class Differences: Online Education in the United States, 2010, published, 2010.

${ }^{3}$ R. Detweiler, "At Last, We Can Replace the Lecture," Chronicle of Higher Education, July 9, 2004, p. B8

${ }^{4}$ I. Jung and I. Rha, "Effectiveness and Cost-Effectiveness of Online Education: A Review of the Literature," Educational Technology, Vol. 40, No. 4, 2000, pp. 57-60.

${ }^{5}$ D. Millard, M. Chouikha, and F. Berry, "Improving Student Intuition via Rensselaer 's New Mobile Studio Pedagogy", ASEE 2007 Annual Conference, Honolulu, HW, June 2007.

${ }^{6}$ C. J. Bonk, The Perfect E-Storm: Emerging Technologies, Enhanced Pedagogy, Enormous Learner Demand, and Erased Budgets (London: The Observatory on Borderless Higher Education, 2004). 